Jurnal Keperawatan Silampari

Volume 5, Nomor 1, Desember 2021

e-ISSN: 2581-1975

p-ISSN: 2597-7482

DOI: https://doi.org/10.31539/jks.v5i1.2834

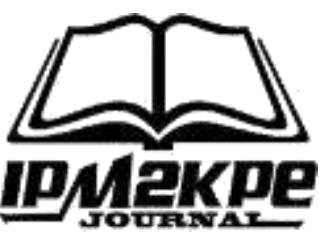

\title{
AROMATERAPI LAVENDER TERHADAP INTENSITAS NYERI HAID (DYSMENORRHEA) PADA MAHASISWI TINGKAT II
}

\author{
Rina Nuraeni ${ }^{1}$, Arin Nurholipah ${ }^{2}$ \\ Sekolah Tinggi Ilmu Kesehatan YPIB Majalengka ${ }^{1,2}$ \\ rinasyifa79@gmail.com ${ }^{1}$
}

\begin{abstract}
ABSTRAK
Penelitian ini bertujuan untuk mengetahui pengaruh aromaterapi lavender terhadap intensitas nyeri haid (dysmenorrhea) pada mahasiswi Tingkat II di STIKes YPIB Majalengka. Metode penelitian yang digunakan adalah penelitian pre eksperiment dengan desain one group pretest-posttest design. Hasil penelitian menunjukkan bahwa kurang dari setengah $(35,0 \%)$ intensitas nyeri haid sebelum aromaterapi lavender adalah berat. Kurang dari setengah $(40,0 \%)$ intensitas nyeri haid sesudah aromaterapi lavender adalah sedang. Hasil analisis bivariat menggunakan uji wilcoxon menunjukkan bahwa nilai $(\rho=0,001)$. Simpulan, Aromaterapi lavender mempunyai pengaruh terhadap intensitas nyeri haid (dysmenorrhea) pada mahasiswi tingkat II di STIKes YPIB Majalengka.
\end{abstract}

Kata Kunci : Aromaterapi Lavender, Dysmenorrhea

\begin{abstract}
This study aims to determine the effect of lavender aromatherapy on the intensity of menstrual pain (dysmenorrhea) in Level II female students at STIKes YPIB Majalengka. The research method used is pre-experimental research with one group pretest-posttest design. The results showed that less than half (35.0\%) of menstrual pain intensity before lavender aromatherapy was severe. Less than half (40.0\%) of the power of menstrual pain after lavender aromatherapy was moderate. The results of the bivariate analysis using the wilcoxon test showed that a value $(\rho=0.001)$. In conclusion, lavender aromatherapy affects the intensity of menstrual pain (dysmenorrhea) in second-level female students at STIKes YPIB Majalengka.
\end{abstract}

Keywords: Lavender Aromatherapy, Dysmenorrhea

\section{PENDAHULUAN}

Kesehatan merupakan keadaan sehat, baik secara fisik, mental, spritual maupun sosial yang memungkinkan setiap orang untuk hidup produktif secara sosial dan ekonomis. Kesehatan bagi wanita yang perlu mendapatkan perhatian bersama salah satunya kesehatan reproduksi. Kesehatan reproduksi bagian penting untuk menyiapkan dan menciptakan sumber daya manusia yang handal serta generasi yang sehat dalam rangka mewujudkan keluarga berkualitas di masa yang akan datang (Kementerian Kesehatan RI, 2019).

Salah satu masalah kesehatan yang menjadi perhatian wanita khususnya remaja adalah masalah menstruasi. Menstruasi merupakan sebuah peristiwa yang fisiologis dan normal bagi setiap wanita. Namun, tidak semua wanita mengalami menstruasi dengan 
normal dan banyak wanita yang mengalami gangguan saat menstruasi atau sewaktu haid yaitu nyeri haid atau dysmenorrhea (Hidayah \& Palila, 2018).

Menurut data Association of Southeast Asian Nations(ASEAN) pada tahun 2018, presentase nyeri haid di negara Singapura sekitar 10-15\%, negara Malaysia 35-40\% dan Thailand 65\%. Di Indonesia angka kejadian nyeri haid tahun 2018 sebanyak 107.673 jiwa (64,24\%), yang terdiri dari 59.671 jiwa $(54,89 \%)$ mengalami nyeri haid primer dan 9.496 jiwa $(9,36 \%)$ mengalami nyeri haid sekunder. Di Jawa Barat tahun 2018, dilaporkan jumlah remaja putri yang reproduktif yaitu yang berusia 10-24 tahun sebanyak 56.598 jiwa. Sedangkan yang mengalami nyeri haid dan datang kebagian kebidanan sebanyak 11.565 jiwa (1,31\%) (Kementerian Kesehatan RI, 2020).

Kejadian nyeri haid pada remaja putri di Kabupaten Majalengka berkisar 50-60\%, hal ini berdasarkan beberapa hasil penelitian diantaranya penelitian Idaningsih \& Oktarini (2019) di SMK YPIB Majalengka yang menyebutkan bahwa presentase kejadian nyeri haid pada remaja sebesar 66,7\% dan penelitian Audina (2019) di STIKes YPIB Majalengka menyebutkan presentase kejadian nyeri haid pada remaja 63,0\%.

Nyeri haid merupakan sejumlah ketidaknyamanan selama hari pertama atau hari kedua menstruasi yang sangat umum terjadi (Prastiwi \& Rohmansyah, 2019). Nyeri haid adalah nyeri (kram) pada daerah perut yang mulai terjadi pada 24 jam sebelum terjadinya perdarahan haid dan dapat bertahan selama 24-36 jam, meskipun pada umumnya berlangsung 24 jam pertama saat terjadi perdarahan haid (Hidayah \& Palila, 2018).

Nyeri haid dibagi menjadi dua macam yaitu nyeri haid primer dan nyeri haid sekunder. Nyeri haid primer yaitu nyeri menstruasi yang timbul tanpa ada sebab yang dapat diketahui. Nyeri haid primer terjadi sejak usia pertama kali datangnya menstruasi disebabkan oleh faktor intrisik uterus dan berhubungan erat dengan ketidakseimbangan hormon steroid seks ovarium, yaitu karena produksi hormon prostaglandin yang berlebih pada fase sekresi yang menyebabkan perangsangan pada otot-otot polos endometrium. Sedangkan nyeri haid sekunder adalah nyeri yang disebabkan oleh simptom penyakit ginekologi seperti endometriosis atau fibroid (Idaningsih \& Oktarini, 2020).

Nyeri haid dapat menimbulkan dampak bagi kegiatan atau aktivitas para wanita khususnya remaja. Nyeri haid membuat wanita tidak bisa beraktivitas secara normal dan memerlukan resep obat. Keadaan tersebut menyebabkan menurunnya kualitas hidup wanita, sebagai contoh siswi yang mengalami nyeri haid primer tidak dapat dapat berkonsentrasi dalam belajar dan motivasi belajar menurun karena nyeri yang dirasakan (Prastiwi \& Rohmansyah, 2019).

Tingkat nyeri dibagi atas skala kategorik (tidak nyeri, sakit ringan, sakit sedang dan sakit berat). Nyeri adalah pengalaman sensori dan emosional yang tidak menyenangkan akibat dari kerusakan jaringan yang aktual atau potensial dan menjadi alasan utama seseorang untuk mencari bantuan perawatan kesehatan. Nyeri terjadi bersama banyak proses penyakit atau bersamaan dengan beberapa pemeriksaan diagnostik atau pengobatan (Prastiwi \& Rohmansyah, 2019).

Cara untuk mengurangi kejadian nyeri haid yaitu dengan cara farmakologi dan non farmakologi. Secara farmakologi menurut, penanganan secara farmakologis yang dapat digunakan pada nyeri haidantara lain adalah pemberian analgetik, terapi hormonal dan terapi dengan obat nonsteroid antiprostaglandin. Sedangkan penanganan non-farmakologis dengan cara olah raga, kompres hangat, minum air putih, istirahat, masage, pemberian nutrisi, terapi dan relaksasi (Idaningsih \& Oktarini, 2020). 
Terapi merupakan salah satu penanganan non farmakologis untuk mengatasi nyeri. Banyak terapi yang bisa dilakukan salah satunya dengan pemberian aromaterapi. Terapi komplementer dengan aromaterapi dapat digunakan sebagai alternatif untuk menurunkan tingkat nyeri. Ketika minyak esensial terhirup, sel-sel reseptor penciuman dirangsang dan impuls ditransmisikan ke pusat emosional otak, atau sistem limbik. Aromaterapi ini dapat memberikan efek santai, dan menenangkan, selain itu meningkatkan sirkulasi darah disamping itu juga termasuk terapi yang murah dan aman serta dapat digunakan untuk mengatasi nyeri haid.

Aromaterapi ialah istilah generik bagi salah satu jenis pengobatan alternatif yang menggunakan bahan cairan tanaman yang mudah menguap, dikenal sebagai minyak esensial, dan senyawa aromatik lainnya dari tumbuhan yang bertujuan untuk memengaruhi suasana hati atau kesehatan seseorang. Aromaterapi adalah suatu pengobatan alternatif yang menggunakan bau-bauan atau wangi-wangian yang berasal dari senyawa-senyawa aromatik. Respon bau yang dihasilkan dari aromaterapi akan merangsang kerja sel neurokimia otak. Oleh karena itu, bau yang menyenangkan akan menstimulasi thalamus untuk mengeluarkan enfekalin yang berfungsi sebagai penghilang rasa sakit alami dan menghasilkan perasaan tenang (Marika et al., 2018).

Aromaterapi merupakan suatu bentuk pengobatan alternatif menggunakan bahan tanaman volatil, banyak dikenal dalam bentuk minyak esensial dan berbagai macam bentuk lain yang bertujuan untuk mengatur fungsi kognitif, mood, dan kesehatan. Aromaterapi dari dari jenis ekstrak tanaman seperti bunga, daun, kayu, akar tanaman, kulit kayu, dan bagianbagian lain dari tanaman dengan cara pembuatan yang berbeda-beda dengan cara penggunaan dan fungsinya masing-masing. Ada banyak jenis aromaterapi, seperti rosemary, sandalwood, jasmine, orange, basil, ginger, lemon, tea tree, ylang-ylang dan lavender (Mokoginta et al., 2021).

Lavender merupakan bunga berwarna ungu kebiruan yang memiliki aroma khas dan lembut sehingga menjadikan rileks saat menghirup aroma jenis ini. Aromaterapi terfavorit adalah bau bunga lavender, bukan hanya disukai tetapi juga karena mempunyai banyak manfaat ketika menghirupnya. Aromaterapi dengan lavender memiliki kelebihan yaitu sederhana, mudah digunakan, dapat disimpan dan dapat digunakan kembali jika mengalami nyeri haid. Pada aromaterapi lavender terdapat kandungan utamanya yaitu linalyl asetat dan linalool, dimana linalyl asetat berfungsi untuk mengendorkan dan melemaskan sistem kerja saraf dan otot yang mengalami ketegangan sedangkan linalool berperan sebagai relaksasi dan sedatif sehingga dapat menurunkan nyeri haid (Marika et al., 2018). Hasil penelitian Marika et al., 2018) di SMA Negeri 5 Semarang menunjukkan bahwa ada pengaruh aromaterapi bunga lavender terhadap penurunan intensitas nyeri haid $(\mathrm{p}=0,002)$. Sejalan dengan penelitian Yunianingrum (2018) di Pondok Pesantren As Salafiyyah dan Pondok Pesantren Ash-Sholihah Sleman menunjukkan bahwa ada pengaruh pemberian aromaterapi lavender terhadap intensitas nyeri haid $(\mathrm{p}=0,001)$.

Alasan peneliti mengambil masalah nyeri haid (dysmenorrhea) pada mahasiswi di perguruan tinggi karena masih banyak mahasiswi yang belum mengetahui cara alternatif penanganan nyeri haid. Hal ini berdasarkan hasil studi pendahuluan di STIKes YPIB Majalengka terhadap 10 mahasiswi tingkat II yang terdiri dari 5 mahasiswi jurusan keperawatan dan 5 mahasiswi jurusan kebidanan. Sebanyak 3 orang (30\%) mengatakan saat haid merasakan nyeri ringan dan masih bisa diatasi serta tidak mengganggu aktivitas kuliah di kampus dan 7 orang $(70 \%)$ mengatakan saat haid sedang sehingga terkadang mengganggu aktivitas perkuliahannya. Dari 10 mahasiswi hanya 2 mahasiswi (20\%) yang mengatakan bahwa ketika haid datang diobati dengan meminum obat paracetamol untuk 
mengatasi nyeri dan 8 mahasiswi (80\%) lainnya hanya istirahat jika terasa nyeri, dan dari 10 mahasiswi tersebut belum ada yang pernah terapi komplementer dengan aromaterapi terapi. Penelitian mengenai aromaterapi lavender ini belum pernah dilakukan pada mahasiswi tingkat II di STIKes YPIB Majalengka, sehingga penelitian ini dapat dijadikan sebagai masukan yang sangat berguna untuk mahasiswa yang mengalami nyeri haid.

\section{METODE PENELITIAN}

Jenis penelitiannya yaitu penelitian pre eksperiment dengan desain one group pretestposttest design. Sampel dalam penelitian ini mahasiswi tingkat II jurusan Keperawatan dan Kebidanan di STIKes YPIB Majalengka sebanyak 20 orang dengan teknik consecutive sampling. Waktu penelitiannya pada tanggal 2 Juni - 28 Juli 2021. Instrumennya menggunakan kuesioner intensitas nyeri dan lembar observasi. Analisis datanya meliputi analisis univariat dengan distribusi frekuensi dan analisis bivariat dengan uji wilcoxon.

\section{HASILPENELITIAN}

\section{AnalisaUnivariat}

Tabel. 1

Gambaran Intensitas Nyeri Haid (Dysmenorrhea) Sebelum Aromaterapi Lavender pada Mahasiswi Tingkat II

\begin{tabular}{|c|c|c|}
\hline $\begin{array}{c}\text { Intensitas Nyeri Haid (Dysmenorrhea) } \\
\text { Sebelum Aromaterapi Lavender }\end{array}$ & $\begin{array}{l}\text { Frequency } \\
(\mathrm{F})\end{array}$ & $\begin{array}{c}\text { Persen } \\
(\%)\end{array}$ \\
\hline Berat & 7 & 35.0 \\
\hline Sedang & 12 & 60.0 \\
\hline Ringan & 1 & 5.0 \\
\hline Tidak nyeri & 0 & 0 \\
\hline Total & 20 & 100.0 \\
\hline
\end{tabular}

Berdasarkan tabel 1 menunjukkan bahwa intensitas nyeri haid (dysmenorrhea) sebelum aromaterapi lavender pada mahasiswi tingkat II di STIKes YPIB Majalengka mayoritas masuk dalam kategori sedang sebanyak 12 orang $(60,0 \%)$.

Tabel. 2

Gambaran Intensitas Nyeri Haid (Dysmenorrhea) Sesudah Aromaterapi Lavender pada Mahasiswi Tingkat II

\begin{tabular}{|c|c|c|}
\hline $\begin{array}{l}\text { Intensitas Nyeri Haid (Dysmenorrhea) } \\
\text { Sesudah Aromaterapi Lavender }\end{array}$ & $\begin{array}{l}\text { Frequency } \\
(\mathrm{F})\end{array}$ & $\begin{array}{c}\text { Persen } \\
(\%)\end{array}$ \\
\hline Berat & 0 & 0 \\
\hline Sedang & 8 & 40.0 \\
\hline Ringan & 12 & 60.0 \\
\hline Tidak nyeri & 0 & 0 \\
\hline Total & 20 & 100.0 \\
\hline
\end{tabular}

Berdasarkan tabel 2 menunjukkan bahwa intensitas nyeri haid (dysmenorrhea) sesudah aromaterapi lavender pada mahasiswi tingkat II di STIKes YPIB Majalengka mayoritas masuk dalam kategori ringan sebanyak 12 orang $(60,0 \%)$. 


\section{Analisis Bivariat}

Tabel. 3

Pengaruh Aromaterapi Lavender terhadap Intensitas Nyeri Haid (Dysmenorrhea) pada Mahasiswi Tingkat II

\begin{tabular}{|c|c|c|c|c|}
\hline $\begin{array}{c}\text { Nyeri pada Siswi yang Mengalami } \\
\text { Dysmenorrhea } \\
\text { (Sebelum-Sesudah) } \\
\end{array}$ & $\mathrm{N}$ & Mean Rank & $\begin{array}{c}\text { Sum of } \\
\text { Ranks }\end{array}$ & $\rho$ value \\
\hline Negative Ranks & $0^{\mathrm{a}}$ & .00 & .00 & \multirow{4}{*}{0.001} \\
\hline Positive Ranks & $14^{\mathrm{b}}$ & 7.50 & 105.00 & \\
\hline Ties & $6^{c}$ & & & \\
\hline Total & 20 & & & \\
\hline
\end{tabular}

Berdasarkan tabel 3 diketahui bahwa nilai negative ranks sebanyak 0 yang artinya dari 20 responden setelah diberi perlakuan aromaterapi lavender intensitas nyerinya tidak ada yang mengalami kenaikan, sedangkan nilai positive ranks sebanyak 14 yang artinya dari 20 responden setelah diberi perlakuan aromaterapi lavender terdapat 14 responden mengalami penurunan intensitas nyerinya dan yang tetap ada 6 responden. Hasil uji statistik dengan uji Wilcoxon pada $\alpha=0,05$ diperoleh $\rho$ value $=0,001$, terdapat pengaruh aromaterapi lavender terhadap intensitas nyeri haid (dysmenorrhea) pada mahasiswi tingkat II di STIKes YPIB Majalengka.

\section{PEMBAHASAN}

\section{Gambaran Intensitas Nyeri Haid (Dysmenorrhea) Sebelum Aromaterapi Lavender}

Berdasarkan hasil penelitian menunjukkan bahwa kurang dari setengah $(35,0 \%)$ intensitas nyeri haid (dysmenorrhea) sebelum aromaterapi lavender pada mahasiswi tingkat II di STIKes YPIB Majalengka adalah berat. Mahasiswi yang mengalami nyeri berat atau sedang saat dysmenorrhea merupakan hal yang wajar atau norma karena saat dysmenorrhea terutama pada hari pertama dan kedua akan mengalami nyeri tidak biasa pada bagian perut bagian bawah.

Hasil penelitian ini sejalan dengan hasil penelitian Megawati \& Muhidin (2018) di Bendo Magetan menunjukkan bahwa sebelum dilakukan pemberian aromaterapi bunga lavender dalam skala nyeri berat yaitu 30\%. Juga sejalan dengan penelitian yang dilakukan Pustikawaty (2018) di Sungai Ambawang Kabupaten Kubu Raya menunjukkan bahwa sebelum pemberian aromaterapi lavender, responden yang mengalami intensitas nyeri haid skala 7 (berat) sebesar $30 \%$.

Nyeri haid merupakan nyeri menusuk yang terasa diperut bagian bawah dan paha, hampir seluruh perempuan dan juga termasuk didalamnya remaja putri pasti pernah merasakan gangguan pada saat menstruasi berupa nyeri menstruasi dengan berbagai tingkatan, mulai dari yang sekedar pegal-pegal di panggul dari sisi dalam hingga rasa nyeri yang luar biasa sakitnya. Nyeri terjadi pada hari pertama dan kedua menstruasi. Rasa nyeri ini akan berkurang setelah keluar darah yang cukup banyak. Nyeri haid dapat menimbulkan dampak bagi kegiatan atau aktivitas para wanita khususnya remaja. Nyeri haid membuat wanita tidak bisa beraktivitas secara normal dan memerlukan resep obat. Keadaan tersebut menyebabkan menurunnya kualitas hidup wanita, sebagai contoh siswi yang mengalami nyeri haid primer tidak dapat dapat berkonsentrasi dalam belajar dan motivasi belajar menurun karena nyeri yang dirasakan (Soeroso, 2016). 
Masih terdapatnya siswi yang mengalami nyeri berat saat $d y$ smenorrhea, maka pihak kampus dapat bekerja sama dengan petugas kesehatan untuk melakukan kegiatan pendidikan kesehatan atau seminar tentang dysmenorrhea dan cara mengatasinya. Bagi mahasiswi untuk melakukan penanganan baik secara farmakologis dengan obat-obatan maupun non farmakolgis seperti dengan aromaterapi untuk mengatasi nyeri.

\section{Gambaran Intensitas Nyeri Haid (Dysmenorrhea) Sesudah Aromaterapi}

Berdasarkan hasil penelitian menunjukkan bahwa kurang dari setengah $(40,0 \%)$ intensitas nyeri haid (dysmenorrhea) sesudah aromaterapi lavender pada mahasiswi tingkat II di STIKes YPIB Majalengka adalah sedang. Sesudah aromaterapi lavender, nyeri yang dialami mahasiswi dari 20 responden yang mengalami kenaikan tidak ada, yang menurun sebanyak 14 responden dan yang tetap ada 6 responden. Hal ini berarti sebagian besar mengalami penurunan, ini terjadi karena adanya manfaat dari aromaterapi lavender yang diberikan kepada mahasiswi terhadap intensitas nyeri. Sejalan dengan hasil Mokoginta et al., (2020) di Kotamobagu menunjukkan bahwa nyeri dysmenorrhea setelah diberikan pemberian aromaterapi bunga lavender yang nyeri sedang $(40,9 \%)$.

Aromaterapi berasal dari kata aroma yang berarti harum atau wangi, dan therapi yang dapat diartikan sebagai cara pengobatan atau penyembuhan. Sehingga aromaterapi dapat diartikan sebagai suatu cara perawatan tubuh atau penyembuhan penyakit dengan menggunakan minyak essensial (essential oil) (Idaningsih \& Oktarini, 2020).

Aromaterapi ialah istilah generik bagi salah satu jenis pengobatan alternatif yang menggunakan bahan cairan tanaman yang mudah menguap, dikenal sebagai minyak esensial, dan senyawa aromatik lainnya dari tumbuhan yang bertujuan untuk memengaruhi suasana hati atau kesehatan seseorang. Aromaterapi adalah suatu pengobatan alternatif yang menggunakan bau-bauan atau wangi-wangian yang berasal dari senyawa-senyawa aromatik. Respon bau yang dihasilkan dari aromaterapi akan merangsang kerja sel neurokimia otak. Oleh karena itu, bau yang menyenangkan akan menstimulasi thalamus untuk mengeluarkan enfekalin yang berfungsi sebagai penghilang rasa sakit alami dan menghasilkan perasaan tenang (Marika et al., 2018).

Pada penelitian ini, setelah mahasiswi mendapatkan pemberian aromaterapi bunga lavender, nyeri yang dialami menurun. Maka pihak kampus dapat bekerja sama dengan petugas kesehatan untuk mengadakan pendidikan kesehatan atau seminar tentang penanganan non famarkologis intensitas nyeri haid (dysmenorrhea) yaitu dengan aromaterapi bunga lavender dan juga melakukan demonstrasi kepada mahasiswa cara melakukan aromaterapi bunga lavender. Bagi mahasiswi dapat melakukan upaya non farmakologis ketika mengalami dysmenorrhea yaitu dengan pemberian aromaterapi bunga lavender.

\section{Pengaruh Aromaterapi Lavender terhadap Intensitas Nyeri Haid (Dysmenorrhea)}

Berdasarkan hasil penelitian menunjukkan terdapat pengaruh aromaterapi lavender terhadap intensitas nyeri haid (dysmenorrhea) pada mahasiswi tingkat II di STIKes YPIB Majalengka. Adanya pengaruh karena adanya kandungan dalam lavender yang dapat memberikan efek terhadap pengurangan nyeri haid.

Hasil penelitian ini sejalan dengan hasil penelitian Yunianingrum (2018) menunjukkan bahwa ada pengaruh aromaterapi lavender terhadap intensitas nyeri haid (dysmenorrhea). Sejalan dengan hasil penelitian Pustikawaty (2018) yang menunjukkan bahwa ada pengaruh aromaterapi lavender terhadap intensitas nyeri haid. 
Hasil penelitian ini sejalan dengan teori bahwa minyak lavender adalah salah satu aromaterapi yang terkenal memiliki efek sedatif, hypnotic dan anti-neurodepresive baik pada hewan maupun pada manusia. Karena minyak lavender dapat memberi rasa tenang, sehingga dapat digunakan sebagai manajemen stres. Kandungan utama dalam minyak lavender adalah linalool asetat yang mampu mengendorkan dan melemaskan sistem kerja urat-urat syaraf dan otot-otot yang tegang. Dikatakan juga linalool menunjukkan efek hypnotic dan anticonvulsive sehingga bunga lavender sangat baik digunakan sebagai aromaterapi. Selain itu, beberapa tetes minyak lavender dapat membantu menanggulangi insomnia, memperbaiki mood seseorang, menurunkan tingkat kecemasan, meningkatkan tingkat kewaspadaan, dan tentunya dapat memberikan efek relaksasi untuk mengurangi nyeri (Idaningsih \& Oktarini, 2020).

Hasil penelitian ini sejalan dengan teori bahwa aromaterapi lavender memiliki kelebihan yaitu sederhana, mudah digunakan, dapat disimpan dan dapat digunakan kembali jika mengalami nyeri haida. Pada aromaterapi lavender terdapat kandungan utamanya yaitu linalyl asetat dan linalool, dimana linalyl asetat berfungsi untuk mengendorkan dan melemaskan sistem kerja saraf dan otot yang mengalami ketegangan sedangkan linalool berperan sebagai relaksasi dan sedatif sehingga dapat menurunkan nyeri haid (Yunianingrum, 2018).

Hasil penelitian ini sejalan dengan teori bahwa pada aromaterapi lavender terdapat kandungan utamanya yaitu linalylasetat dan linalool, dimana linalyl asetat berfungsi untuk mengendorkan dan melemaskan sistem kerja saraf dan otot yang mengalami ketegangan sedangkan linalool berperan sebagai relaksasi dan sedatif sehingga dapat menurunkan nyeri haid (Megawati \& Muhidin, 2019). Aromaterapi bunga lavender banyak digunakan di bidang klinis kebidanan dan ginekologi psikomatis. Aromaterapi bunga lavender digunakan sebagai perawatan untuk mengatasi nyeri, mengurangi rasa sakit pascaoperasi caesar, mengurangi depresi dan kecemasan pada ibu post partum, dan menurunkan nyeri haid (Idaningsih \& Oktarini, 2020).

Terbukti bahwa aromaterapi lavender terhadap intensitas nyeri haid (dysmenorrhea) pada mahasiswi tingkat II. Maka pihak kampus dapat menambah materi penanganan non farmakologis dengan aromaterapi lavender kepada mahasiswa baik teori maupun praktis dan juga dapat bekerja sama dengan petugas kesehatan untuk mengadakan pendidikan kesehatan atau seminar tentang penanganan non-famarkologis intensitas nyeri haid (dysmenorrhea) yaitu dengan aromaterapi bunga lavender dan juga melakukan demonstrasi kepada mahasiswa cara melakukan aromaterapi bunga lavender. Bagi mahasiswi dapat melakukan upaya non-farmakologis ketika mengalami dysmenorrhea yaitu dengan pemberian aromaterapi bunga lavender.

\section{SIMPULAN}

Aromaterapi lavender mempunyai pengaruh terhadap intensitas nyeri haid (dysmenorrhea) pada mahasiswi tingkat II di STIKes YPIB Majalengka tahun 2020.

\section{SARAN}

Bagi STIKes YPIB Majalengka, agar menambah referensi penanganan non farmakologis dengan aromaterapi lavender kepada mahasiswa baik teori maupun praktis dan juga dapat bekerja sama dengan petugas kesehatan untuk mengadakan pendidikan kesehatan atau seminar tentang penanganan non famarkologis intensitas nyeri haid (dysmenorrhea) yaitu dengan aromaterapi bunga lavender dan juga melakukan demonstrasi kepada mahasiswa cara melakukan aromaterapi bunga lavender. Bagi mahasiswa, agar 
dapat melakukan upaya non farmakologis ketika mengalami dysmenorrhea yaitu dengan pemberian aromaterapi bunga lavender.

\section{DAFTAR PUSTAKA}

Hidayah, N., \& Palila, S. (2018). Kesiapan Menghadapi Menarche pada Remaja Putri Prapubertas Ditinjau dari Kelekatan Aman Anak dan Ibu. Psympathic : Jurnal Ilmiah Psikologi, 5(1), 107-114. https://doi.org/10.15575/psy.v5i1.202

Audina, C. (2019). Pengaruh Kompres Hangat, Pemberian Minuman Jahe dan Kunyit terhadap Penurunan Derajat Nyeri Haid pada Mahasiswi Kebidanan di Stikes $\begin{array}{llll}\text { YPIB Majalengka } & \text { Tahun } & 2019 . & \text { http://e- }\end{array}$ journal.stikesypib.ac.id/index.php/JK/article/view/59/40

Idaningsih, A., \& Oktarini, F. (2020). Pengaruh Efektivitas Senam Dismenore terhadap Penurunan Intensitas Nyeri Dismenore pada Remaja Putri di SMK YPIB Majalengka Kabupaten Majalengka Tahun 2019. Syntax Literate; Jurnal Ilmiah Indonesia, 5(2), 55. https://doi.org/10.36418/syntax-literate.v5i2.923

Kementerian Kesehatan RI. (2019). Laporan Nasional Riskesdas 2018. Jakarta: Kementerian Kesehatan RI

Kementerian Kesehatan RI. (2020). Profil Kesehatan Indonesia Tahun 2019. Jakarta: Kementrian Kesehatan RI

Marika, A., Mu, N., \& Widyawati, M. N. (2018). Pengaruh Pemberian Aromaterapi Lavender terhadap Penurunan Intensitas Nyeri Haid pada Remaja Putri di SMA Negeri 5 Semarang. Poltekkes Kemenkes Semarang. http://repository.poltekkessmg.ac.id/index.php?p=show_detail\&id=13713\&keywords=

Megawati, I. R., \& Muhidin, M. (2019). Pengaruh Relaksasi dengan Aromaterapi terhadap Perubahan Intensitas Dismenorea. https://ejournal.lppmdianhusada.ac.id/index.php/jk/article/view/70

Mokoginta, F. F., Jama, F., \& Padhila, N. I. (2020). Lilin Aromaterapi Lavender Dapat Menurunkan Tingkat Dismenore Primer. Window of Nursing Journal, 1(2), 113-122. DOI: 10.33096/won.v1i2.309

Prastiwi, B. K., \& Rohmansyah, N. A. (2019). Pengaruh Latihan Imagery untuk Mengurangi Nyeri Haid pada Pembelajaran Penjasorkes. Seminar Nasional Keindonesiaan FPIPSKR, 201-210. http://conference.upgris.ac.id/index.php/snk/article/view/580

Pustikawaty, R. (2018). Pengaruh Aromaterapi Lavender terhadap Skala Nyeri Haid Siswi Kelas X Sekolah Menengah Atas Negeri 1 Sungai Ambawang Kabupaten Kubu Raya. Technology, 1(1), 1-17. https://jurnal.untan.ac.id/index.php/jmkeperawatanFK/article/view/16204

Soeroso, S. (2016). Masalah Kesehatan Remaja. Sari Pediatri, 3(3), 189. https://doi.org/10.14238/sp3.3.2001.189-97

Yunianingrum, E. (2018). Pengaruh Kompres Hangat dan Aromaterapi Lavender terhadap Penurunan Nyeri Dismenore Primer pada Remaja Putri di Pondok Pesantren As Salafiyyah dan Pondok Pesantren Ash- Sholihah Sleman. Poltekkes Kemenkes Yogyakarta. http://eprints.poltekkesjogja.ac.id/1428/ 